\title{
Analysis of seismic attributes to recognize bottom simulating reflectors in the Foz do Amazonas basin, Northern Brazil
}

Laisa da Fonseca Aguiar*, Antonio Fernando Menezes Freire, Luiz Alberto Santos, Ana Carolina Ferreira Dominguez, Eloíse Helena Policarpo Neves, Cleverson Guizan Silva and Marco Antonio Cetale Santos

Universidade Federal Fluminense

Copyright 2019, SBGf - Sociedade Brasileira de Geofísica

This paper was prepared for presentation during the $16^{\text {th }}$ International Congress of the Brazilian Geophysical Society held in Rio de Janeiro, Brazil, 19-22 August 2019.

Contents of this paper were reviewed by the Technical Committee of the $16^{\text {th }}$ International Congress of the Brazilian Geophysical Society and do not necessarily represent any position of the SBGf, its officers or members. Electronic reproduction or storage of any part of this paper for commercial purposes without the written consent of the Brazilian Geophysical Society is prohibited.

\section{Abstract}

Foz do Amazonas basin is located at the northern portion of the Brazilian Equatorial Margin, along the coastal zone of Amapá and Pará states. Seismic reflection is one method used to identify the occurrence of gas hydrates, as they give rise to well-marked reflectors that simulate the seafloor, known as Bottom Simulating Reflectors (BSR). This study aims to investigate BSRs associated with the presence of methane hydrates in the Foz do Amazonas Basin through the application of seismic attributes. Firstly, a comparison between seismic amplitudes from the seafloor and BSR was cross correlated to validate the inferred seismic feature. Then, seismic attributes Envelope and Second Derivative were chosen for successfully highlight the BSR in a seismic section. The results also showed an inversion of polarities in the signal between the seafloor (positive polarity) and the BSR (negative polarity). The integrated use of these approaches allowed validating the level of the BSR in seismic section 0239-0035 and inferring the presence of gas hydrates, revealing to be a useful tool for interpreting the distribution of gas hydrates in the Foz do Amazonas Basin, particularly in the Amazonas Cone.

\section{Introduction}

The occurrence of natural gas hydrates on continental margins worldwide, including the Foz do Amazonas Basin, is of growing interest due to its energy potential (Kvenvolden, 1993; Sloan, 2003; Joshi et al., 2017). Also noteworthy are the environmental aspects related to methane hydrates: their consequences on the planet's climate, as an enhancer of the greenhouse effect, and in the context of instability of the seafloor (Kvenvolden, 1993).

The presence of methane hydrates can be inferred from Bottom Simulating Reflectors (BSRs) on seismic reflection data. A BSR is a seismic reflector parallel to the seafloor that coincides with the base of the Gas Hydrate Stability Zone (GHSZ), characterized by a negative reflectivity, i.e. polarity opposite to the seafloor (Kvendolven, 1993; Hyndman \& Spence, 1992). The BSR is inferred to coincide with the phase boundary, and separate solid hydrates above from free gas below (Kvendolven, 1993).
Seismic attributes are excellent tools for seismic interpretation and are increasingly important for the exploration of hydrocarbons (Taner et al., 1994). The choice of an attribute depends on the specific reservoir environments, the mathematical foundation of the attribute and what is this attribute sensitive to (Chen \& Sidney, 1997). There are several studies that uses the application of seismic attributes in order to examine and investigate the presence of gas hydrates in different regions around the world (Coren et al., 2001; Satyavani et al., 2008; Ojha \& Sain, 2009).

The Foz do Amazonas Basin is located on the Brazilian Equatorial Margin and includes the submarine deposits of the Amazonas River (Soares et al., 2008), one of the world's largest deep-sea fans (Damuth and Kumar, 1975). The presence of gas hydrates within the Amazon deep-sea cone has been inferred from BSRs (Sad et al., 1998), and recently confirmed by seafloor sampling of fluid seeps (Ketzer et al., 2018).

This study aims to identify which seismic attributes are more effective to locate the presence of BSRs related to methane hydrates in the Foz do Amazonas Basin. In this work, the software Petrel was used for the interpretation of $2 \mathrm{D}$ reflection seismic data obtained from the Exploration and Production Database (BDEP) of the National Petroleum Agency (ANP).

\section{Method}

The first step in this work was the loading of 74 seismic sections of 2D surveys, provided by the National Petroleum Agency (ANP) - Exploration and Production Database (BDEP), into the software Petrel. After the quality control of all the seismic data, line 0239-0035 (Figure 1) was selected because it presents interesting features, possibly related to gas hydrates.

Two graphs were created to analyze the behavior of the possible BSR in comparison to the seafloor, in two distinct sections (section 1 and section 2), in order to assure the BSR location in the seismic.

Afterwards, several seismic attributes were tested to highlight the identified BSR in line 0239-0035 and, consequently, to infer the lower boundary of the gas hydrate stability zone. Two attributes were chosen that best highlighted the BSR: Envelope and Second Derivative of the Envelope. 


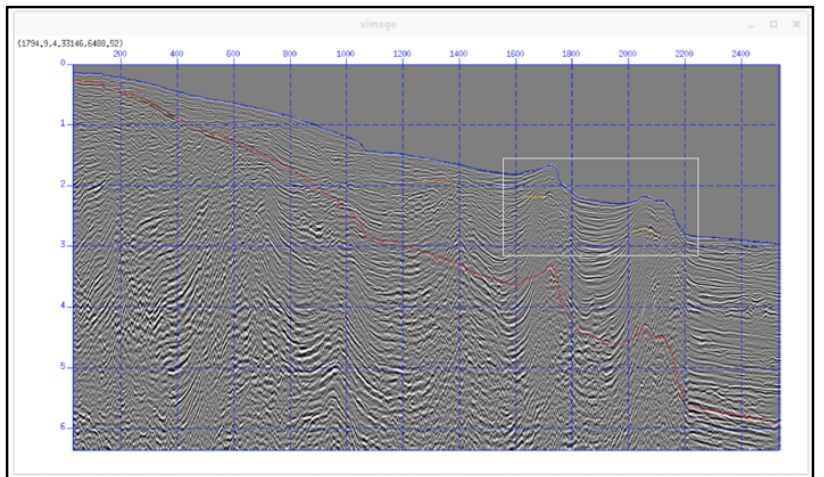

Figure 1 - Line 0239-0035. The highlighted area in white represents the region of interest for this project. The blue line corresponds to the seafloor, the red line represents the seismic multiple and the yellow lines refer to possible BSRs.

Figure 2 represents line 0239-0035 for this project. This line was analyzed in two sections, where possible BSRs are observed to cross-cut strata that are not parallel to the seafloor.

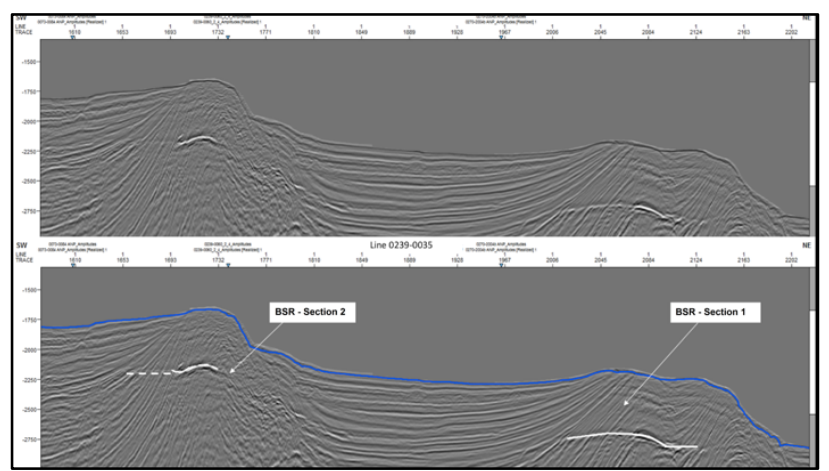

Figure 2 - Seismic line 0239-0035 with no interpretation (top) and with the two sections of BSR (white lines).

\section{Results and Discussion}

Firstly, in order to validate the location of the BSRs in seismic and infer the presence of methane hydrates associated to these features, it was compared the seismic amplitudes for seafloor and possible BSR in the two sections of line 0239-0035, in which these seismic reflectors are observed. It was possible to identify negative amplitude reflections interpreted as BSRs, an indicative of the existence of methane hydrates in the Foz do Amazonas Basin. The amplitude data are plotted in Figures 3 and 4, and the inversion in polarity between the seafloor (positive) and the BSR (negative) is easily recognized.

According to Kvendolven (1993), the seismic reflector that coincides with the lower limit of the gas hydrate stability zone can be defined by reversed polarity, in comparison to the seafloor coefficients. In the graphs above, even if the reversed polarity is not in terms of absolute values, there is clearly an approximation between the values of these amplitudes (except for a few points), which validates the identification and level of the BSR in both sections 1 and 2 .

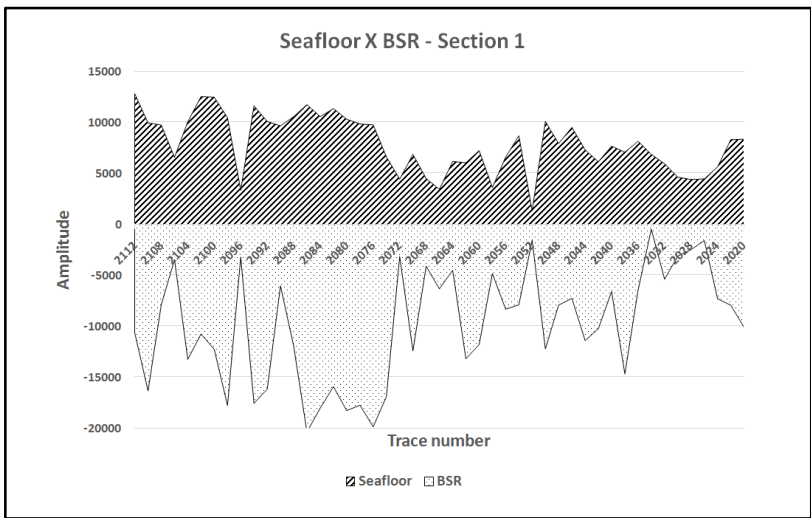

Figure 3 - Seismic amplitudes of line 0239-0035 on the seafloor and the BSR - section 1.

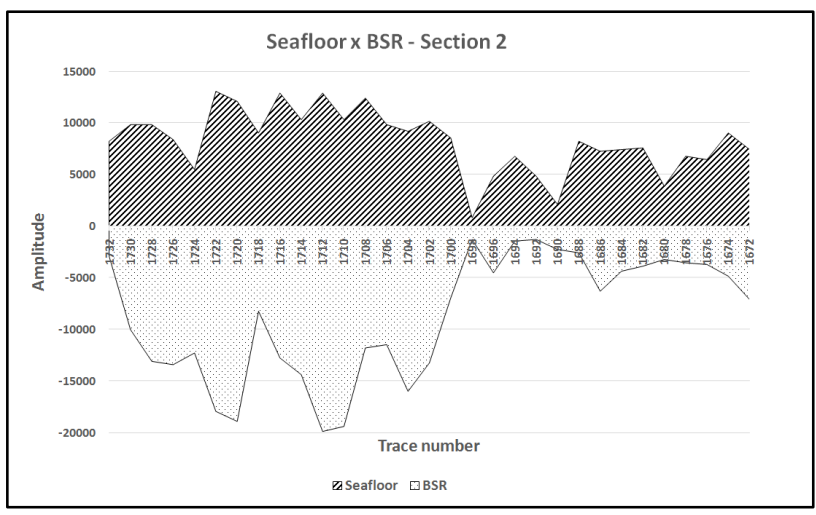

Figure 4 - Seismic amplitudes of line 0239-0035 on the seafloor and the BSR - section 2.

BSR amplitude is extremely sensitive to small gas concentrations located below the hydrate stability zone (Holbrook et al., 2002), and some authors suggest that BSRs appear discontinuous at higher frequencies, forming a series of strong reflections that are parallel to the seafloor but laterally discontinuous (Dillon et al., 1996). This could be an explanation for the small intervals in which the absolute values of seismic amplitudes between the seafloor and the BSR are dissimilar. The concentration of gas hydrates, above the BSR, and of free gas below it, vary and cause the intensity of the reflector to vary locally. Therefore, the BSR will be stronger the greater the saturations of gas hydrates and free gas, which increases the impedance contrast.

Finally, the last step in this work was the application of seismic attributes. The first seismic attribute applied to the section was the Envelope (or instantaneous amplitude). As this attribute is directly related to the acoustic impedance contrast, its application is significant for the characterization of methane hydrates. Figure 5 shows line 0239-0035 with the Envelope attribute applied. 


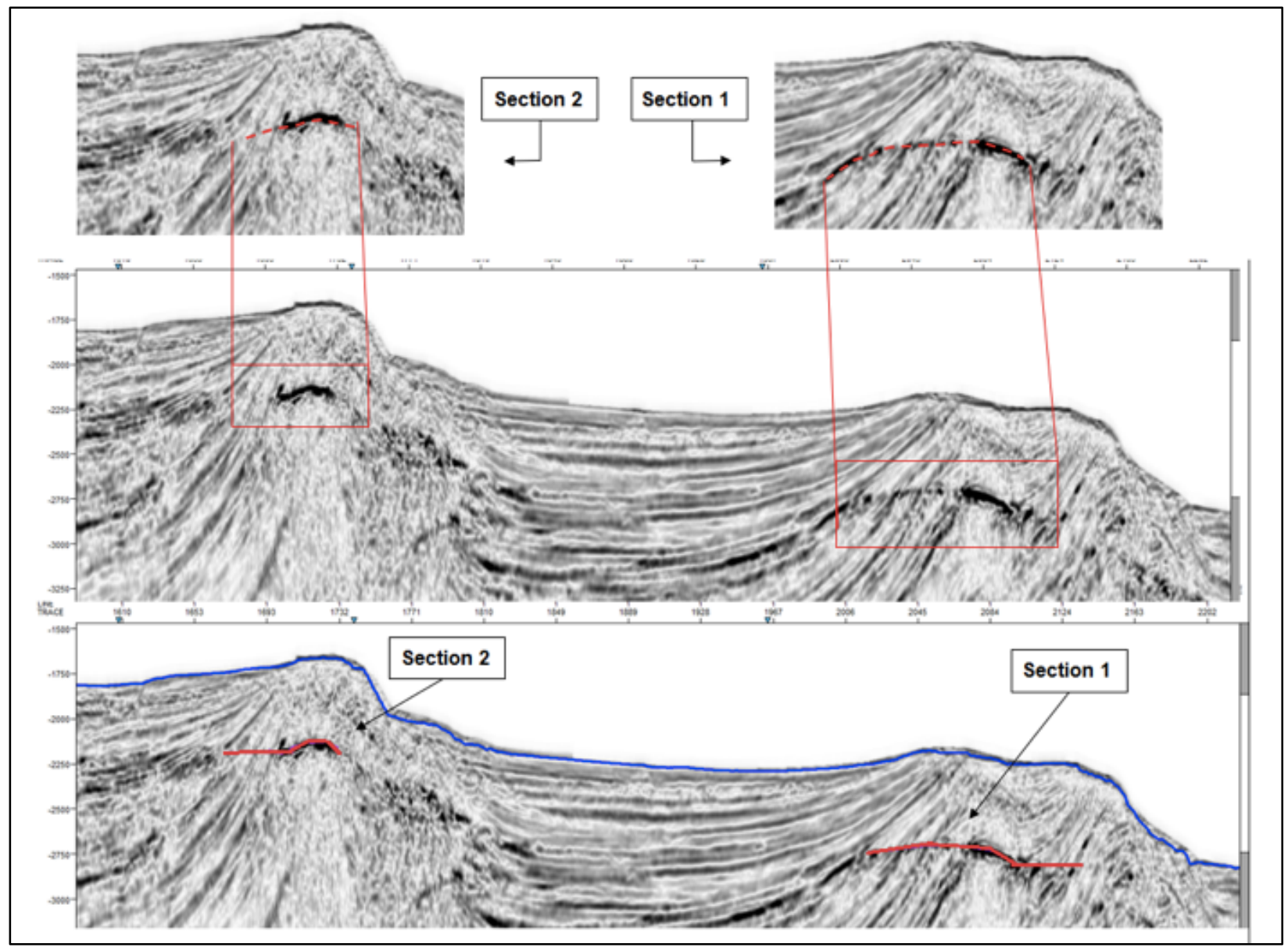

Figure 5 - Seismic section 0239-0035 with Envelope attribute applied. The two sections of BSR are highlighted in red.

The use of the Envelope attribute enhances the visualization and identification of BSR, especially in the interval between the numbers of traces 2112-2022 for section 1 and 1732-1676 for section 2, since this attribute works as a good discriminator for lithological and stratigraphic changes in reservoirs and accumulations of gas and fluids (Taner, 1992; Chen \& Sidney, 1997), therefore it highlights the presence of free gas trapped beneath the BSR.

The second seismic attribute used to infer the presence of methane hydrates was the Second Derivative of the Envelope. Figure 6 illustrates section 0239-0035 with the Second Derivative of the Envelope applied and possible portions of the BSR not interpreted and interpreted, respectively.

Like the Envelope, the use of the Second Derivative of Envelope enhances the visualization of the BSR of both passages in the seismic section. According to Taner (1992), this attribute provides a good subsurface representation and highlights less smooth lithology changes.

\section{Conclusions}

The integration of geophysical methods is valuable for a more accurate characterization of the subsurface. In this study, two approaches were proposed: a comparison of seismic amplitudes and the application of seismic attributes, which together addressed the identification of BSRs. These approaches reveal to be a useful tool for interpreting the distribution of gas hydrates in the Foz do Amazonas Basin.

The results showed that there is an inversion of polarities in the signal between the seafloor (positive polarity) and the BSR (negative polarity), although this inversion is not always in absolute values. In addition, the attributes chosen for this study - Envelope and Second Envelope Derivative - were able to enhance the visualization of BSR. The integrated use of these methods allowed validating the identification of the BSR in line 0239-0035 and inferring the presence of gas hydrates.

\section{Acknowledgments}

The authors are thankful to the National Petroleum Agency (ANP) for the permission to use the seismic data of the Foz do Amazonas Basin from the database of Exploration and Production (BDEP). 


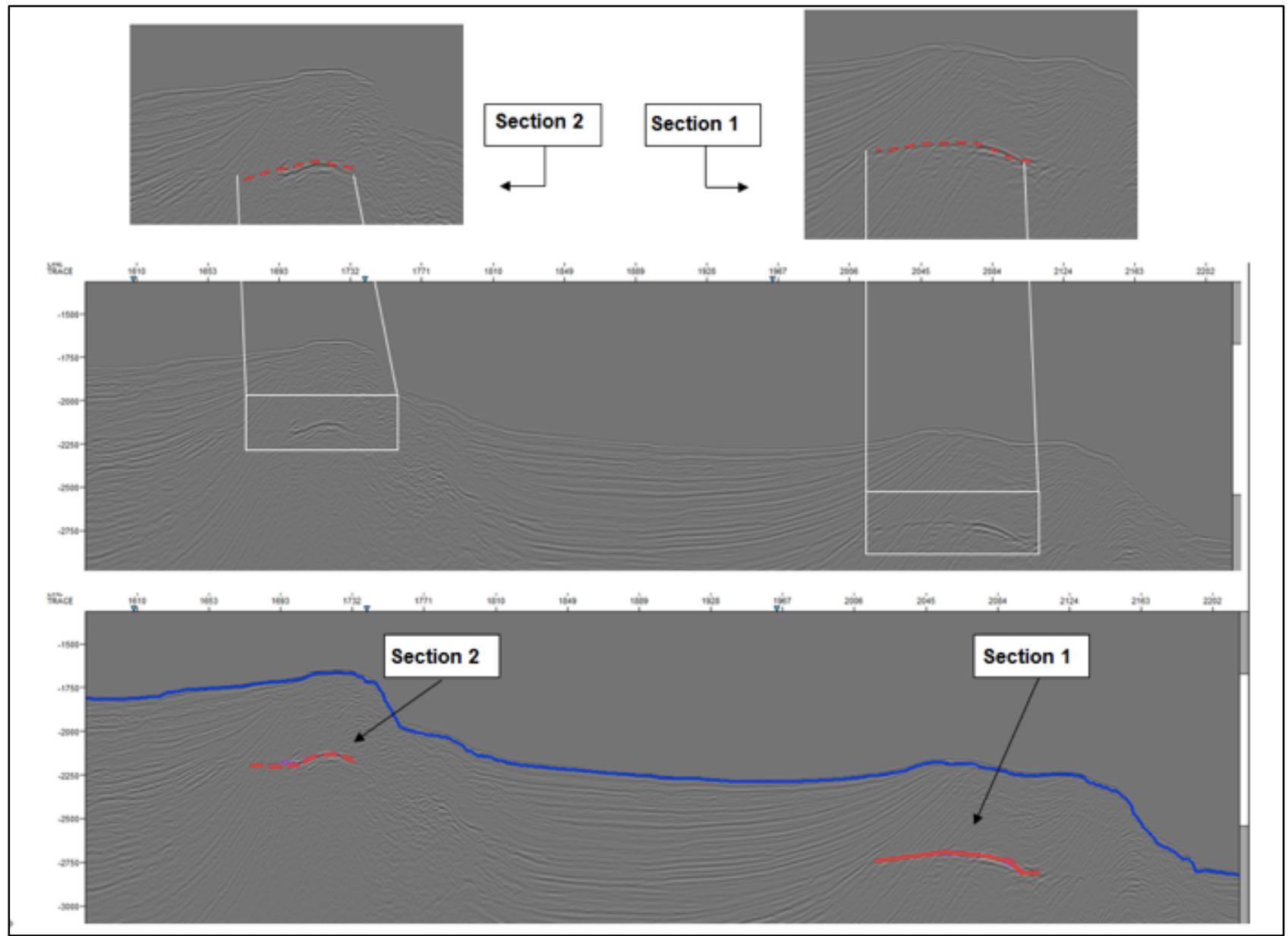

Figure 6 - Seismic section 0239-0035 with the Second Derivative of Envelope attribute applied. The two sectors of BSR are highlighted in red.

\section{References}

Chen Q. and Sidney S. 1997. Seismic attribute technology for reservoir forecasting and monitoring. The Leading Edge, 16(5):445-448.

Coren, F., Volpi, V., \& Tinivella, U. (2001). Gas hydrate physical properties imaging by multi-attribute analysisBlake Ridge BSR case history. Marine Geology, 178(1-4), 197-210.

Damuth J.E. and Kumar N. 1975. Amazon Cone: morphology, sediments, age, and growth pattern. Geological Society of America Bulletin, 86(6):863878.
Dillon W.P., Hutchinson D.R. and Drury R.M. 1996. Seismic reflection profiles on the Blake Ridge near Sites 994, 995, and 997. In Proceedings of the Ocean Drilling Program, Initial Reports, 164:47-56.

Holbrook W.S., Gorman A.R., Hornbach M., Hackwith K.L., Nealon J., Lizarralde D. and Pecher I.A. 2002. Seismic detection of marine methane hydrate. The Leading Edge, 21(7):686-689.

Hyndman R.D. \& Spence G.D. 1992. A seismic study of methane hydrate marine bottom simulating reflectors. Journal of Geophysical Research: Solid Earth, 97(B5):6683-6698. 
Joshi A.K., Pandey L. and Sain K. 2017. Identification of BSR and estimation of gas hydrate from well-log data at NGHP-01-04A and 11A in the Krishna-Godavari Basin, Eastern Indian Margin. In: 2017 SEG International Exposition and Annual Meeting. Houston, Texas. Society of Exploration Geophysicists, p. 3483-3487.

Ketzer, J.M., Augustin, A., Rodrigues, L.F., Oliveira, R., Praeg, D., Pivel, M.A.G., dos Reis, A.T., Silva, C. and Leonel, B., 2018. Gas seeps and gas hydrates in the Amazon deep-sea fan. Geo-Marine Letters, 38(5), pp.429-438.

Kvendolven K.A. 1993. Gas hydrates-geological perspective and global change. Reviews of Geophysics, 31(2):173-187.

Ojha, M. and Sain, K. 2009. Seismic attributes for identifying gas-hydrates and free-gas zones: application to the Makran accretionary prism. Episodes, 32(4), 264-270.

Sad, A.R.E., Silveira, D.P., Machado, D.A.P., Silva, S.R.P. and Maciel, R.R. 1998. Marine gas hydrates evidence along the Brazilian coast. In Proc. AAPG international conference and exhibition. Rio de Janeiro, Brazil. Nov (pp. 8-11).

Satyavani, N., Sain, K., Lall, M., \& Kumar, B. J. P. 2008. Seismic attribute study for gas hydrates in the Andaman Offshore India. Marine Geophysical Researches, 29(3), 167-175.

Sloan Jr, E.D. 2003. Fundamental principles and applications of natural gas hydrates. Nature, 426(6964), p.353.

Soares A.V.Jr., Costa J.B.S., Hasui Y. 2008. Evolução da Margem Atlântica Equatorial do Brasil: Três Fases Distensivas. Geociências (São Paulo), 27:427-437.

Taner M.T. 1992. Attributes Revisited - Rock Solid Images. Houston, Texas (Revised Sep. 2000), p. 3 - 27.
Taner M.T., ODoherty R., Schuelke J.S., Baysal E. 1994. Seismic attributes revisited. In: SEG Technical Program Expanded Abstracts, Tulsa, Society of Exploration Geophysicists, p. 1104-1106. 